\title{
A Conversation with Edward Boyden
}

\author{
INTERVIEWER: REBECCA LESHAN \\ Director, Banbury Center, Cold Spring Harbor Laboratory
}

\begin{abstract}
Edward Boyden is the Y. Eva Tan Professor in Neurotechnology at the Massachusetts Institute of Technology (MIT), Associate Professor of Biological Engineering and Brain and Cognitive Sciences at MIT's Media Lab, McGovern Institute for Brain Research, and Koch Institute, and has been selected to be an Investigator of the Howard Hughes Medical Institute.
\end{abstract}

Rebecca Leshan: I wonder if you could give a quick snapshot of your research.

Dr. Boyden: If we want to understand the brain, we have three technological needs: to see what's going on in the brain with high-speed precision, to map the molecules and the organization of the brain, and to control the high-speed dynamics. We've been working a lot on extending tool sets into these three directions. For control, we've been trying to perfect optogenetic control of neurons and also to develop noninvasive ways to focus the effects of electricity deep in the brain. For mapping the brain, we've been working on ways to physically blow up the brain until it's up to a thousand times bigger in volume so that you can map the very finest connections.

\section{Rebecca Leshan: Physically?}

Dr. Boyden: That's right. So we can take a piece of brain tissue and magnify it physically - it grows before your very eyes - until it could be a thousand times or more larger in volume.

Rebecca Leshan: And this is expansion microscopy?

Dr. Boyden: That's right. And finally, to watch the highspeed dynamics of the brain, we've been trying to work out, basically, the opposite of optogenetics: to get neurons to report their electrical activity in the form of light. That's a hard problem, so we've been developing robots that could do directed evolution and make these molecules in the laboratory.

Rebecca Leshan: What you do feels so different from what a lot of researchers are doing. You don't have a specific disease state that you're focused on. You're really about developing tools and that has such a huge impact on the field. How does that differ in the way that you approach a research topic or the field?

Dr. Boyden: We don't focus on a single disease because we want to solve all of them. I've thought a lot about the different diseases and also basic science questions like
"What is a memory?" or "How does a decision take place?" And it was very clear that there are so many problems, and so our strategy is to take a step back: What's the underlying problem that, if we solved it, would solve all these other problems. So by building these tool sets and giving them out to thousands of groups - we do some basic science in our group but most of the work we do is either collaborative or through teaching the tools to other people - we think we can help solve all these problems over an extended period of time.

Rebecca Leshan: That really fits with your training because you started as an engineer, right? Which I think of as "What can we build?" or "How can we build it?"

Dr. Boyden: Well, I started my training in chemistry for two years working on an origins of life project, of all things. Then I switched schools and started studying physics and electrical engineering. By that point I knew a lot of stuff, but I needed a really good problem to work on. It seemed like the brain - I was always very philosophically inclined, ever since I was a kid - had real consequences for understanding the human condition, but there are also lots of practical things we could do if we could help heal the sick or prevent disease.

Rebecca Leshan: This not only spans a lot of disease states but you're spanning a lot of model organisms and even, hopefully for the future, to think about humans. Has that been difficult, or has that been an easy transition between different types of models?

Dr. Boyden: The basic science we do, thinking like a physicist, is all on very small organisms. I would love to solve a simple organism, like the worm $C$. elegans or a larval zebrafish over the next five to 15 , who-knows-howmany years it will take to do that. But as far as building tools that everyone can use, we do our own human experiments. We do our own mouse experiments. We try to really validate these technologies in a wide variety of species so that everybody — as many people as we can [help], anyway - can use our technologies.

(C) 2018 Boyden. This article is distributed under the terms of the Creative Commons Attribution License, which permits unrestricted reuse and redistribution provided that the original author and source are credited. 
Rebecca Leshan: In line with thinking about everybody being able to use your technologies, you have in a remarkable way been very open with all of your protocols and your technologies, getting things out there, even before they're published sometimes. Is that a philosophy you've always had or is that something new, as you became a principal investigator?

Dr. Boyden: I think it's kind of the obvious path. If you build a tool and nobody uses it, what's the point? We've always had the policy of giving out everything for free to academics and nonprofit scientists and so forth. That's both charitable, but it's also self-interested. Again, what's the point of our existence if we don't do anything useful?

Rebecca Leshan: Is there anything at the symposium that surprised you? Is there anything that has really inspired you here? Or even if not here, in the field today that's really exciting you outside of your own work?

Dr. Boyden: Lots of things. I feel like there is a lot of interesting physics that's being discovered about the brain. We're hearing about new forms of energy like ultrasound, and other ways of interfacing to the brain using clever and novel strategies from different parts of science. I also think there's a real interesting connection that's forming between the basic science and the translational side, so hearing about people's studies about how mapping the brain can lead to new targets for treating depression with electrical stimulation - these kinds of topics really show the power, not just of technology, but bridging the science/ translational gap through real experiments and real results.

Rebecca Leshan: Are you collaborating with clinicians in some of the work that you do?

Dr. Boyden: A lot. We've given our tools to literally thousands of groups at this point. We have close collaborations with maybe a hundred groups where we really work side by side with people. For example, there's a way of noninvasively stimulating the human brain through focusing electric fields through some clever tricks that we've stumbled across, and we are working now with a number of people. In fact, we have requests out from dozens of groups to collaborate to try to apply this in different kinds of diseases ranging from Alzheimer's to tinnitus to depression and everything in between.

Rebecca Leshan: How much interaction do you have with industry? What you're doing is very innovative and I can imagine a lot of biotech and pharma companies are very interested.

Dr. Boyden: We've done technology transfer to a lot of pharmaceutical companies and device companies. Several start-up companies are also licensing technology from us, all the way from discovery to treatments. We also spun out several companies of our own. I co-founded, with Professor Li-Huei Tsai at MIT, a company to try to develop media that you could watch or hear to treat Alzheimer's disease.

We have other projects, too, like this expansion method. If you want to detect diseases early-I think for something like eight out of the top 10 leading causes of death, if you can catch the diseases earlier, you could help people more. So what's the problem with detecting diseases early? Well, it's very subtle, the changes that occur early in a disease. So this expansion method, where we blow up a piece of tissue a thousand times or more, if you could use that to blow up, for example, a cancer biopsy and diagnose it earlier - "Oh, that's not good ... oh, that's benign..."that could really help save a lot of lives. We've spun that out as a company, as well.

Rebecca Leshan: Have you thought about tools for other fields like immunology? Or are you squarely staying within the brain?

Dr. Boyden: The brain is like a mountain. The climb to the top is a long road, and along the way there's lots of points in time where you can kind of spin out other projects. Last year, for example, we published our first paper in the field of cancer biology. It didn't mention the brain once. We worked with some pathologists from Harvard Medical School, and we showed that if we expand human breast cancer biopsies, for which pathologists disagree about the diagnosis up to half the time, we could actually help train a machine-learning algorithm better to discriminate between these different cases, from benign to something that one might worry about. We're finding that the brain is so complex that if you build a tool that can confront the complexity of the brain, it might be able to help solve a lot of other problems as well.

Rebecca Leshan: Your background is quite varied and the way that you approach problems reflects interdisciplinary thinking. Do you also expect that of those you train? Is that an advantage to you? Or if somebody came to you and said, "I've studied neuroscience my entire career and I want to work with you." Is that off-putting?

Dr. Boyden: I think to really see if somebody can innovate well you have to watch them in action. We have a grad student in my group who's working on a really cool project. His professional training was as a photographer. He was actually a professional photographer. But if you're a classically trained photographer you know a lot of chemistry, too. You know how to develop pictures and so forth. So he's now leading one of our most out-of-the-field projects.

We have two graduate students who never finished college. They dropped out, but it became pretty clear that they have a lot of problem-solving skills and they're now both leading projects that are quite exciting. So I really think you have to understand how people think, and there's a lot of emotional components to being an innovator as well. A lot of our technologies, once we have figured out how to create them-which requires a lot of failure and a lot of wisdom-gathering through failure - once we understand the problem at a deeper level, the technologies are not so hard to build. It's the understanding of the problem at a deep level that's so difficult.

Rebecca Leshan: You mentioned having failures along the way. What has been the biggest hurdle that you've overcome? Or what is still the biggest hurdle for you in the work that you're doing? 
Dr. Boyden: I've looked back at our group's work over the last 12 years and there's a model of innovation that I think emerges, which really has "failure" as an integral part of it. Step 1 is to pick a really big problem to work on, and I think all the big problems are pretty obvious, like "Let's see what's going on in the brain," or "Let's control everything in the brain." The second step is to think backward from that problem and survey all the different disciplines of science and engineering and try to systematically think of how we would go about solving it. This is actually the approach that Karl Deisseroth and I applied when we started thinking up optogenetics. We just started thinking about mechanical and optical and electrical, magnetic ... just started to go through all the laws of physics trying to think of the best way to control neural activity, back in the year 2000 when we were both students. So, I really think that one can be very systematic and having interdisciplinary training can help with that.

Step 3 is what I call "constructive failures." We try things out, and a lot of them will fail, but they'll show us things that nobody's seen before. They'll show us what you might call "wisdom," this kind of elusive appreciation of reality that's hard to get just by thought or by reading.

\section{Rebecca Leshan: Experience.}

Dr. Boyden: Yeah. And Step 4 is "design." So we now know the nature of the reality of it better than before; let's go design the ultimate technology. With a lot of our technologies-like expansion microscopy or automatic patch clamping or optogenetics or voltage imaging, the list goes on-we followed something like that pattern. It allows us to do things that are very orthogonal to what people are doing because we understand the problem for its own sake, at its own level.

Rebecca Leshan: That's quite methodological. How much of a component of your process involves a little bit of luck here and there?

Dr. Boyden: Well, the "wisdom-gathering"-where we notice things people haven't seen before-I mean, that's obviously serendipitous. When we did the first optogenetics experiments, it basically worked on the first try. We didn't have to improve the molecules; we didn't have to mutate them. They were fast enough, high enough amplitude, and safe enough that they worked on, essentially, the first try. So yeah, there's a lot of luck involved. But I think you can optimize your luck. Sometimes I claim that what we're trying to do is "serendipity engineering": we do on purpose what otherwise might take a long time if it's only accidental.

Rebecca Leshan: Your description of the process and the failures sounds very much like the entrepreneurial spirit, where you see start-ups coming through and there's a certain level of failure you need to gain that experience in the world. I know you teach some courses that have an entrepreneurial component, is that right?

Dr. Boyden: I teach one class for the MIT business school.
Rebecca Leshan: Is this method part of what you're imparting to your students?

Dr. Boyden: I think there is an attitude [of] failing fast, and I'm not sure that's exactly what I believe in. I believe more in "you learn through the failure" and that pivots into the real solution. I don't think it's a failure per se, it's just that you have to learn before you can succeed, and the learning requires you to do things that cause you to fail. I don't think it's a failure per se because in the end it is actually a success. And most of the great technologies, you could argue, are failure reboots. You know there are lots of examples where something didn't quite work until somebody went "Hey, computers are faster nowadays," or "Hey, we have better genome sequencing" and then suddenly what was a bad idea has turned into a good one.

Rebecca Leshan: I've heard a story that the seminal experiment in the optogenetics work you had started at 1 a.m. Please tell me that's not true.

Dr. Boyden: It is true. The way we divvied up the labor was Karl Deisseroth did the transfections of the genes and then I was patch clamping them and shining the light on the cells and, yeah, it more or less worked on the first try.

Rebecca Leshan: Do you think he did that on purpose, leaving your part until 1 a.m.?

Dr. Boyden: Oh that's just when I had time on the rig; that wasn't him. I was doing the work actually in Richard Tsien's group, my thesis adviser's group, so this is before Karl was a professor.

Rebecca Leshan: Do I have it right that this was sort of your side project initially?

Dr. Boyden: Yeah, it was sort of an independent side project. We actually published the first optogenetics paper 2 months before I turned in my PhD thesis with Richard Tsien and Jennifer Raymond, which was all about cerebellum-dependent motor learning. Then things kind of took off. I found myself applying for faculty jobs just weeks after turning in my thesis.

Rebecca Leshan: I have another "maybe" misconception to clear up. Is it true that first paper was rejected by $\mathrm{Sci}$ ence and Nature?

\section{Dr. Boyden: It was, yeah.}

Rebecca Leshan: At this meeting, are you getting people coming up to you? Trainees and students wanting to talk to you about what's next?

Dr. Boyden: Oh, yeah. Well, optogenetics as a tool set has become pretty mature. There're obviously some things that have to be improved but most of the tool set's in a pretty good state right now. But optogenetics by itself doesn't solve the brain. I think we have to also get those really good molecular and wiring maps of the brain. And we also really need to have good high-speed imaging of the dynamics of the brain. So almost all of our effort, on technology anyway, is focused on those two areas. Why can't we see ... why can't we evolve all sorts of 
fluorescent indicators of every neural signaling pathway? And through these robotic - and, now we're starting to work in artificial intelligence methods to solve this as well - can we actually start generating in a systematic way new kinds of fluorescent reporter. And then for imaging the wiring, we're getting a lot of technologies based on our expansion method that will hopefully allow people to routinely extract diagrams of the wiring of the brain.

Rebecca Leshan: I'm glad you mentioned artificial intelligence. Do you think that discovering more about the human brain is able to inform the development of artificial intelligence? How much are you getting from the reverse? Learning from artificial intelligence and processes that are being built on their own, are there things that you're taking away from that?

Dr. Boyden: We have 30,000-ish genes in the human genome, and who knows how many hundreds or thousands of cell types in the body. These data sets are obviously going to be very large. If we were to map one human brain, just one, and digitize it to single-molecule resolution and put the data on little hard drives and stacked them up, the tower of hard drives would reach into outer space from the Earth's surface. That's just one brain, too. We're definitely going to need new kinds of algorithmic thinking and we're starting to use quite a bit of that in evaluating the kinds of data we're getting. 


\section{$\$_{\text {CSH\& }}^{\infty}$ Cold Spring Harbor Symposia SYMPOSIA}

\section{A Conversation with Edward Boyden}

Cold Spring Harb Symp Quant Biol 2018 83: 239-242 originally published online February 25, 2019

Access the most recent version at doi:10.1101/sqb.2018.83.037325
Creative This article is distributed under the terms of the
Commons http://creativecommons.org/licenses/by/4.0/, which permits unrestricted
License reuse and redistribution provided that the original author and source are credited.

Email Alerting Receive free email alerts when new articles cite this article - sign up in Service the box at the top right corner of the article or click here. 